\title{
Metastatic Spread to the Pituitary
}

\author{
Ilan Shimon \\ Institute of Endocrinology, Beilinson Hospital, Petach Tikva, and Sackler School of Medicine, Tel-Aviv University, \\ Petach Tikva, Israel
}

\section{Keywords}

Diabetes insipidus · Hypopituitarism · Metastasis · Pituitary

\begin{abstract}
The pituitary fossa is an uncommon site for metastatic tumor spread. Metastatic lesions to the sellar area derived mostly from breast, lung, renal, prostate, and colon cancers, and rarely from other solid and hematologic malignancies. Almost every cancer has been reported as a source of pituitary metastasis. Pituitary metastasis can involve both the anterior and posterior lobes, but the neuro-hypophysis is mainly involved. Clinical manifestations include diabetes insipidus, hypopituitarism, headache, visual disturbances, ophthalmoplegia, and also compression of adjacent structures by aggressive tumor masses. Metastatic spread to the pituitary from a distant primary malignancy is commonly associated with metastases to other tissues and poor prognosis, unless efficient systemic targeted medical treatment is available for the primary cancer (melanoma, lymphoma).
\end{abstract}

(c) 2020 S. Karger AG, Base

\section{Introduction}

Pituitary metastasis (PM) is a rare complication of advanced malignancy, first reported by L. Benjamin in 1857 as a case of melanoma spread to the pituitary identified in an autopsy [1], and later in 1913, Cushing [2] reported

karger@karger.com

(C) 2020 S. Karger AG, Basel

www.karger.com/nen

Karger! this unique phenomenon as the cause of diabetes insipidus. Pituitary/sellar metastases are rare and account for only $1 \%$ of all operated pituitary masses $[3,4]$ and $<1 \%$ of all intracranial metastatic lesions. Most cases are asymptomatic and are incidentally discovered during an autopsy or in patients during end-stage malignant course, and characteristic symptoms are reported in $<20 \%$ [4]. However, during the last two decades, with the improvement of neuroimaging techniques and the increased survival of cancer patients, most cases of PM are generally diagnosed as a complication of disseminated malignancies with metastatic spread to other organs $(80 \%$ of the reported cases). Only in $20-30 \%$ of the cases, PM is the initial presentation of an unknown primary tumor and precedes the diagnosis of malignancy [5]. The majority of affected patients are diagnosed between the age of 45 and 74 years with a mean age of $\sim 60$ years $[5,6]$. The male-to-female distribution is similar $[5,7]$.

\section{Primary Cancer Location}

Among males, lung cancer is the most common primary cancer $(46 \%)$, and in females, breast carcinoma constitutes half of the cases $[4,5,7,8]$. Altogether, breast and lung cancer account for $60 \%$ of the PMs. These are followed by kidney, prostate, and colon cancer $(3-5 \%$ each). However, almost every cancer type can metastasize to the pituitary fossa, including solid cancers (melanoma, 
Fig. 1. Sellar MRI of 2 patients with PM. a A 41-year-old female with metastatic breast carcinoma presenting with headache, right optic neuropathy, diabetes insipidus, and hypopituitarism (from the author's private collection). b A 47-year-old male with metastatic atypical bronchial carcinoid presenting with bitemporal hemianopsia and hypopituitarism. Reproduced with permission from Shimon et al. [20].
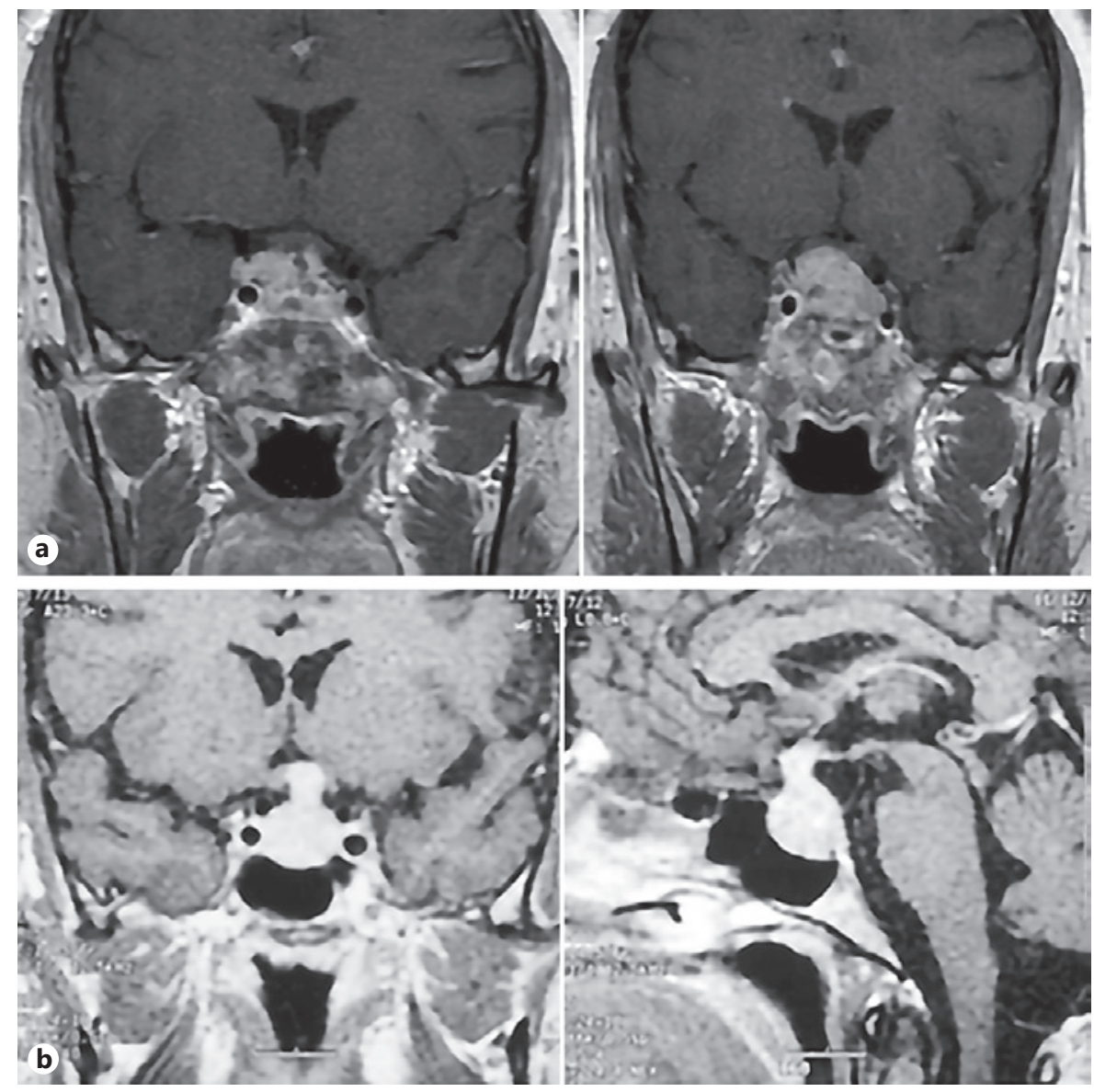

thyroid, pancreas, endometrium, liver, bladder, ovary, sarcoma, germ-cell tumor, neuroendocrine, stomach, pharynx) and hematologic malignancies (lymphoma, leukemia, multiple myeloma). About 3-4\% of all cases derive from an unknown primary cancer.

\section{Symptoms at Presentation}

Patients with PM present in $~ 50 \%$ of the cases with diabetes insipidus [4-9], which rarely occurs in patients with pituitary adenomas. Other symptoms and signs include visual damage (30\%), ophthalmoplegia (25\%), headache/retroorbital pain (20\%), and also fatigue, weight loss, nausea/vomiting, and cognitive deterioration in $5-10 \%$ of the affected subjects $[4-5,7-8]$. Anterior pituitary deficiency is reported in $25-45 \%$ of the cases [4-9] with central hypothyroidism and low cortisol levels identified frequently. Hyperprolactinemia is depicted in $80 \%$ of the patients with PMs [8].

\section{Pituitary Imaging: How to Differentiate Metastasis from a Pituitary Adenoma?}

Pituitary MRI usually reveals a non-homogenous invasive sellar mass (Fig. 1), sometimes appearing as dumbbell-shaped tumor due to indentation of the diaphragm sellae. Loss of the posterior lobe bright spot can be seen. However, sometimes it is difficult to radiologically differentiate PM from pituitary adenoma or other sellar pathologies. Nevertheless, the presence of sellar bone erosion without sellar enlargement may support the diagnosis of PM. Functional imaging with PET-FDG to differentiate adenoma from metastasis is of limited value as pituitary adenoma can also appear as hypermetabolic sellar mass. A few cases of metastatic spread to pituitary adenomas have also been reported in the literature [10, 11 . 


\section{How Can Malignant Cells Reach the Pituitary?}

The most common symptom of PM is diabetes insipidus, reflecting the frequent involvement of the posterior pituitary. Anyway, the anterior lobe is reported to be involved in many cases. Metastatic spread to the posterior lobe and infundibulum occurs by direct hematogenous spread through the inferior hypophyseal artery. The anterior pituitary lacks direct arterial blood supply, and metastatic cells may travel through the hypothalamushypophyseal portal circulation system, supplying the entire anterior lobe. Metastatic deposits can reach the pituitary fossa also by direct extension from parasellar malignancies and through leptomeningeal spread.

\section{Diagnosis}

In a patient with an aggressive sellar mass, rapid tumor growth, and involvement of adjacent structures, diabetes insipidus, and/or cranial neuropathies should raise the possible diagnosis of PM, especially when these symptoms progress rapidly in older patients. If the patient has a background of malignant disease, the diagnosis of metastatic involvement is straightforward. However, a pituitary lesion may represent the first sign of an otherwise unknown malignancy [12], and diagnosis may be difficult. Metastatic lesion should be suspected during surgery because of the unusual appearance of the lesion that tends to be firm, invasive, and vascular, but diagnosis depends on the histological features of the resected tumor. Anyway, the diagnosis of PM is confirmed by histological investigation in the minority (34\%) of cases $[5,13]$, whereas in $66 \%$ of the patients it is based on sellar imaging combined with the appropriate clinical scenario and symptoms.

\section{Treatment}

Complete surgical resection of PMs is usually impossible because these metastases are often diffuse and invasive, but surgery is still indicated when suprasellar extension of a metastasis results in chiasmal damage and visual deterioration, or when histological assessment of the sellar tumor is required for the precise diagnosis of the primary cancer and decision on the preferred treatment. Surgery by the trans-sphenoidal route can improve visual-field defects, headache, and ophthalmoplegia in the majority of affected cases. Stereotactic sellar radiosurgery is also an effective, noninvasive, and safe method of ameliorating the compressive symptoms of PMs in patients with widespread metastases and expected short survival [14]. Definitive tissue diagnosis by surgery may prevent unnecessary radiotherapy to the sellae or the need for other systemic treatments when benign pituitary disease is confirmed histologically [15]. Surgery with/or sellar radiation can improve local symptoms but are not expected to increase the survival rate, thus the treatment aim is mostly palliative.

Anterior pituitary function should be carefully studied and hormonal replacement initiated as required. Diabetes insipidus treated with desmopressin (administered nasally or orally) can improve the quality of life and prevent sodium/water imbalance. Systemic targeted medical treatment is usually not efficient when diffuse metastatic spread together with PM is apparent. However, patients with pituitary involvement by melanoma, lymphoma, or leukemia may potentially benefit from chemotherapy or immunotherapy if diagnosed and treated appropriately $[16,17]$.

\section{Prognosis}

Patients with PMs have poor prognosis, and usually most patients die within 12 months from diagnosis $[5,7$, $18,19]$. The prognosis is related to the stage and type of the primary tumor. The cause of death is usually progression of the primary malignancy and not related directly to the pituitary metastatic lesion [5]; thus, surgery or sellar radiotherapy are only palliative treatments and unable to increase survival. In the last years, series of patients with PMs and improved prognosis were reported. Patients were treated using a multimodal approach, including pituitary surgery, sellar radiotherapy, hormonal replacement, and chemotherapy, and achieved an extended median survival of 16 months $[13,19]$. In a recent systematic review including a total of 657 cases with PMs, patients with metastasis derived from lung cancer (31\% of the cohort) tend to have shorter survival (9 months), compared to 22 months in breast cancer patients (26\% of the cohort) and 30 months for those with kidney cancer (8\%) and PM [6]. Interestingly, targeted radiotherapy to the pituitary given to $69 \%$ of the affected subjects was associated with significant improvement in the survival time (16 months) over untreated patients (6 months), with a trend favoring stereotactic over conventional radiotherapy [6]. Nevertheless, surgical treatment did not have any impact on the overall survival [6]. 


\section{Conclusion}

Pituitary metastases are rare but discovered now more frequently in patients with disseminated cancer due to novel medical treatments and extended survival of cancer patients. Breast and lung cancer are the leading malignancies associated with PMs, but almost any malignant tumor has been previously reported as a potential source for sellar metastasis. Patients present with diabetes insipidus, anterior pituitary hypofunction, visual damage, and ophthalmoplegia. Beside hormonal replacement treatments for posterior and anterior hypofunction, pituitary surgery, and/or directed radiation are generally palliative. Prognosis is usually poor unless efficient targeted medical treatment is available for the primary cancer.

\section{Disclosure Statement}

The author has received research grants, consulting, and lectureship fees from Novartis, Medison, and Pfizer.

\section{Funding Sources}

The author did not receive any specific grant from any funding agency for this study.

\section{References}

1 Chiang MF, Brock M, Patt S. Pituitary metastases. Neurochirurgia (Stuttg). 1990 Jul;33(4): 127-31.

2 Cushing H. Concerning diabetes insipidus and the polyuria of the hypophysial origin. Boston Med Surg J. 1913;168(25):901-10.

3 Freda PU, Post KD. Differential diagnosis of sellar masses. Endocrinol Metab Clin North Am. 1999 Mar;28(1):81-117.

4 Komninos J, Vlassopoulou V, Protopapa D, Korfias S, Kontogeorgos G, Sakas DE, et al. Tumors metastatic to the pituitary gland: case report and literature review. J Clin Endocrinol Metab. 2004 Feb;89(2):574-80.

5 Habu M, Tokimura H, Hirano H, Yasuda S, Nagatomo Y, Iwai Y, et al. Pituitary metastases: current practice in Japan. J Neurosurg. 2015 Oct;123(4):998-1007.

6 Ng S, Fomekong F, Delabar V, Jacquesson T, Enachescu C, Raverot G, et al. Current status and treatment modalities in metastases to the pituitary: a systematic review. J Neurooncol. 2020 Jan;146(2):219-27.

7 He W, Chen F, Dalm B, Kirby PA, Greenlee JD. Metastatic involvement of the pituitary gland: a systematic review with pooled individual patient data analysis. Pituitary. 2015 Feb;18(1):159-68.
8 Al-Aridi R, El Sibai K, Fu P, Khan M, Selman WR, Arafah BM. Clinical and biochemical characteristic features of metastatic cancer to the sella turcica: an analytical review. Pituitary. 2014 Dec;17(6):575-87.

9 Fassett DR, Couldwell WT. Metastases to the pituitary gland. Neurosurg Focus. 2004 Apr; 16(4):E8.

10 Magnoli F, Finzi G, Riva C, Capella C. Renal cell carcinoma metastatic to a pituitary FSH/ LH adenoma: case report and review of the literature. Ultrastruct Pathol. 2014 Dec;38(6): 430-7.

11 Abe T, Matsumoto K, Iida M, Hayashi M, Sanno N, Osamura RY. Malignant carcinoid tumor of the anterior mediastinum metastasis to a prolactin-secreting pituitary adenoma: a case report. Surg Neurol. 1997 Oct;48(4):38994.

12 Ruelle A, Palladino M, Andrioli GC. Pituitary metastases as presenting lesions of malignancy. J Neurosurg Sci. 1992 Jan-Mar;36(1):51-4.

13 Patel KR, Zheng J, Tabar V, Cohen MA, Girotra M. Extended survival after surgical resection for pituitary metastases: clinical features, management, and outcomes of metastatic disease to the sella. Oncologist. 2019 Nov;24:1-9.

14 Kano H, Niranjan A, Kondziolka D, Flickinger JC, Lunsford LD. Stereotactic radiosurgery for pituitary metastases. Surg Neurol. 2009 Sep;72(3):248-55.
15 Goulart CR, Upadhyay S, Ditzel Filho LF, Beer-Furlan A, Carrau RL, Prevedello LM, et al. Newly diagnosed sellar tumors in patients with cancer: a diagnostic challenge and management dilemma. World Neurosurg. 2017 Oct;106:254-65.

16 McCutcheon IE, Waguespack SG, Fuller GN, Couldwell WT. Metastatic melanoma to the pituitary gland. Can J Neurol Sci. 2007 Aug 34(3):322-7.

17 Kenchaiah M, Hyer SL. Diffuse large B-cell non Hodgkin's lymphoma in a 65-year-old woman presenting with hypopituitarism and recovering after chemotherapy: a case report. J Med Case Reports. 2011 Oct;5(1):498.

18 Javanbakht A, D’Apuzzo M, Badie B, Salehian B. Pituitary metastasis: a rare condition. Endocr Connect. 2018 Aug;7(10):1049-57.

19 Morita A, Meyer FB, Laws ER Jr. Symptomatic pituitary metastases. J Neurosurg. 1998 Jul;89(1):69-73.

20 Shimon I, Hadani M, Nass D, Zwas ST. Malignant bronchial carcinoid tumor metastatic to the pituitary in a thyroid carcinoma patient: successful treatment with surgery, radiotherapy and somatostatin analog. Pituitary. 2004;7(1):51-7. 